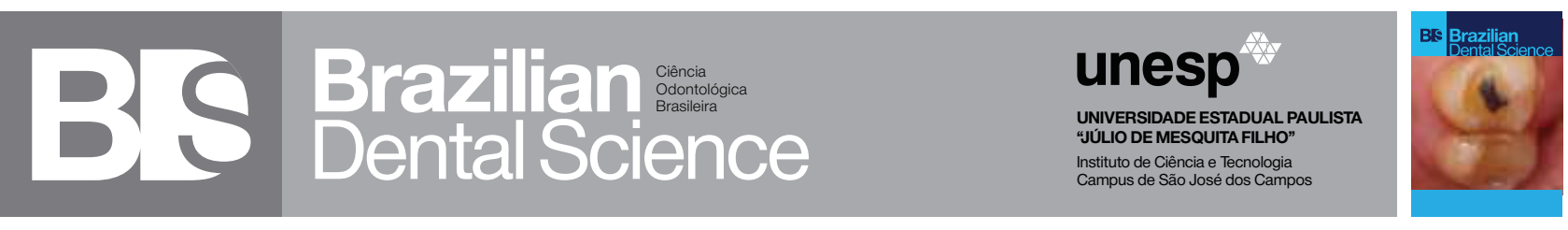

\title{
Clinical evaluation of multiple-surface ART restorations: three-year follow-up
}

Avaliação clínica de restaurações de ART de superfícies múltiplas: acompanhamento de três anos

Daniela Francisca Gigo CEFALY ${ }^{1}$, Terezinha Jesus Esteves BARATA ${ }^{2}$, Eduardo BRESCIANI ${ }^{3}$, Ticiane Cestari FAGUNDES ${ }^{4}$, Maria Fidela de Lima NAVARRO ${ }^{5}$

1 - Tech Projetos Tecnológicos Ltda - São Carlos - SP - Brazil.

2 - Department of Preventive Dentistry and Oral Rehabilitation - Dental School - Federal

University of Goiás - UFG - Goiânia - Goiás - Brazil.

3 - Institute of Science and Technology - UNESP - Univ Estadual Paulista - School of Dentistry Department of Restorative Dentistry - São José dos Campos - São Paulo - Brazil.

4 - Araçatuba School of Dentistry - UNESP - Univ Estadual Paulista - Restorative Dentistry - Araçatuba - São Paulo - Brazil.

5 - Department of Operative Dentistry - Endodontics and Dental Materials - Bauru School of Dentistry - University of São Paulo - USP Bauru - SP - Brazil.

\section{ABSTRACT}

Objective: To evaluate the performance of multiple-surface restorations made with two different glass-ionomer cements (GICs) in permanent teeth using the Atraumatic Restorative Treatment (ART). Material and methods: A total of 60 restorations were placed in schoolchildren (9-16 years of age) by two dentists using standard ART procedures. The restorations were randomly divided into two groups. Thirty cavities were filled with high-viscosity GIC (Ketac Molar-3M ESPE) and 30 cavities were filled with resin-modified GIC (Fuji VIII-GC Corp.). Two calibrated independent examiners carried out the evaluation according to ART criteria. Data were statistically analyzed using multiple logistic regression models to evaluate the variables associated with the success (GIC, operator, Class type). The 95\% Confidence Intervals (CI) for success were based on the binomial distribution. A difference was statistically significant if $\mathrm{p}<0.05$. Results: In a 3-year follow-up, 57 restorations were evaluated. In the Ketac Molar group, 3 restorations were not evaluated, 21 were considered successful and 6 unsuccessful. In the Fuji VIII group, 28 restorations were considered successful and 2 unsuccessful. The logistic regression model showed that the combination of the variables was only statistically significant in relation to survival of ART restorations ( $\mathrm{p}=$ 0.036). There were no statistically significant differences between the groups taking each variable into account. The best performance included the combination: Fuji VIII, operator B and Class I involving two or more tooth surfaces. Conclusion: The clinical performance of the multiplesurface ART restorations of both materials was considered satisfactory with a high success rate after 3 years.

\section{RESUMO}

Objetivo: Avaliar o comportamento clínico de restaurações de superfícies múltiplas, realizadas com dois cimentos de ionômero de vidro (CIVs) em dentes permanentes, utilizandose o Tratamento Restaurador Atraumático (ART). Material e Métodos: 60 restaurações foram realizadas em escolares (idade entre 9 - 16 anos) por dois dentistas utilizando-se os procedimentos convencionais do AR. As restaurações foram distribuídas aleatoriamente em dois grupos. Trinta cavidades foram restauradas com CIV de alta viscosidade (Ketac Molar 3M ESPE) e 30, com CIV modificado por resina (Fuji VIII-GC Corp.). Dois avaliadores calibrados e independentes realizaram a avaliação segundo os critérios do ART. Os resultados foram submetidos à análise estatística utilizando-se modelos de regressão logística múltipla, avaliando-se o sucesso em função das variáveis associadas (CIV, operador e tipo de cavidade). Intervalos de confiança de $95 \%$ para o sucesso foram baseados na distribuição binomial. Diferenças estatisticamente significantes ocorreram se $\mathrm{p}<0,05$. Resultados: Em 3 anos de acompanhamento 57 restaurações foram avaliadas. No grupo do Ketac Molar, 3 restaurações não foram avaliadas, 21 obtiveram sucesso e 6 falharam. No grupo do Fuji VIII, 28 restaurações obtiveram sucesso e 2 falharam. A combinação de variáveis foi somente significante em relação à sobrevida das restaurações $(p=0,036)$. Não houve diferenças entre os grupos considerando-se cada variável independentemente. A combinação apresentando melhor desempenho foi: Fuji VIII, operador B e Classe I envolvendo duas ou mais superfícies dentárias. Conclusão: O desempenho clínico de restaurações de ART de superfícies múltiplas foi considerado satisfatório para ambos os materiais testados, apresentando altos índices de sucesso após três anos.

\section{KEYWORDS}

Glass-ionomer cements; Atraumatic Restorative Treatment; Clinical trial.

\section{PALAVRAS-CHAVE}

Cimento de ionômero de vidro; Tratamento restaurador atraumático; Pesquisa clínica. 


\section{INTRODUCTION}

$\mathrm{T}$ he Atraumatic Restorative Treatment (ART) approach combines the preventive component with the restorative procedure, and has the potential to be minimally invasive and to maximally preserve the tooth structure $[1,2,3]$. It involves the removal of infected tooth tissues using hand instruments, and the cavity including adjacent pits and fissures is restored using a filling material, usually a glassionomer cement (GIC) [1, 3, 4].

The ART was recommended by World Health Organization (WHO) for bringing restorative dental treatment appropriate for the management of dental caries in communities with poor infrastructures and inadequate oral health systems $[1,2,4,5]$. It also has applications in industrialized countries, especially for: (I) very young children who are being introduced to oral care, (II) patients who experience extreme fear or anxiety about dental procedures, (III) mentally and/or physically handicapped patients, (IV) home-bound elderly and residents of nursing homes, and (V) patients in high-risk caries clinics who can benefit from ART as an intermediate treatment to stabilize conditions $[2,5,6]$. This approach requires neither electricity nor plumbed water and, therefore, can be applied in almost any setting and under field conditions [5].

The success of ART as a caries management approach is supported by 25 years [1]. The ART approach is an important corner stone in the building of global oral health [1]. The ART approach have been carried out in different countries around the world [1, 2, 3, 5] The survival of single-surface ART restorations in the primary and permanent dentition shows good results, on average $86.1 \%$ and $91.7 \%$ after 3 years, respectively $[7,8,9,12]$, while the success rate of multiple-surface ART restorations in the same period is about $77 \%$ in the permanent dentition [8] and $48.7 \%$ in the primary dentition [9]. It has been observed that the main circumstances for failed multiple-surface ART restoration were: restorations missing, restoration fractures, and unacceptable occlusal wear $[4,10,11,12]$. These facts may be attributed to: inadequate mechanical properties of the GIC's to resist occlusal forces, inadequate GIC's placement with inclusion voids, large cavity sizes, operators inexperience and inadequate cavity preparation with hand instruments, lack of chairside assistance, blood and salivary contamination $[4,7,13]$.
GICs have been the initial choice of restorative materials for ART approach because of its capacity to bond chemically to enamel and dentin, as well as its fluoride releasing property. In addition, the hand-mixed GIC does not require electrically driven equipment $[1,3,7]$.

Thus, efforts to improve the performance of ART restorations have been made, involving the formulation of GIC's specially developed for ART approach such as high-viscosity GIC (HV GIC) and resin-modified glass-ionomer cements (RM GIC's) $[14,15]$. More recently, the RM GIC restorative, Fuji VIII (GC) was marketed for the ART; this GIC is chemically cured $[16,17]$.

Due to the insufficient information in the literature regarding the longevity of multiplesurface ART restorations and the lack of evidence of its effectiveness for high-caries populations, this study was designed to compare the clinical performance of two different GIC's: a high-viscosity and resin-modified cement using the ART approach to restore multiple-surface cavities in permanent teeth.

\section{MATERIAL AND METHODS}

\section{SAMPLING PROCEDURE}

This study was approved by the Local Ethics Committee of the Bauru School of Dentistry, USP, according to the guidelines of the Declaration of Helsinki. The procedures were conducted in two suburban public schools. The schoolchildren's parents were informed of the study through the school and were free to opt for their children not to participate. The participant children were then screened clinically to assess their treatment needs. The inclusion criteria were: posterior permanent teeth with carious lesions extending into dentin involving two or more surfaces and accessible with hand instruments. Teeth with pulpal involvement such as: pulp exposure, history of pain, and/or the presence of a swelling or fistula, as well as, judged to be unrestorable according to ART approach were excluded from the study $[1,3,4]$. In these cases, the child and parent were advised to seek care at Basic Health Centers. Children were included in this study only after parental or guardian consent with the respective signature on the consent form. The children also assented.

Two operators, both PhD students, and one chairside assistant provided all the examinations 
and ART restorations, after they had received a training course in the ART approach. All standard procedures as described in the ART approach were followed $[1,3,4]$. The record included: name, address, age, school, and medical and dental history, plus the family and friend's address and phone.

The sample of this study consisted of 60 posterior permanent teeth of schoolchildren, which were divided into two groups. Thirty cavities were filled with high viscosity GIC (Ketac Molar - 3M ESPE) and 30 cavities were filled with resin-modified GIC (Fuji VIII-GC Corp.), respectively control and test groups. In order to homogenize the sample the GICs were chosen randomly. The specifications of the glass-ionomer cements are summarized in Table 1.

\section{CLINICAL PROCEDURES}

The treatment was carried out inside classrooms using only hand instruments and portable lights. Patients were positioned on a table available in the schools combined with a foldable cushion and a soft headrest in order to achieve a proper patient-to-operator position. Cotton wool rolls were used for isolation according to ART approach. The tooth surface was cleaned with wet cotton pellet for removal of debris and plaque. Cavity access was achieved with the use of enamel hatchet (Duflex-SS White, Petrópolis, Brazil). The next step was removal of decalcified tissue with an excavator, first at the dentinenamel junction and further at floor of the cavity. A retentive groove was made on the axio-buccal and axio-lingual line angles of the proximal box, parallel to dentin-enamel junction and the tooth external surface, with a fine spoon excavator (Duflex-SS White, Petrópolis, Brazil). The cavity was cleaned with a small wet cotton pellet and dried with dry cotton pellet. When necessary, pulpal protection with calcium hydroxide cement (Hydro C, Dentsply, Petrópolis, Brazil) was used in deep cavities. The conditioning of the tooth structure was carried out with a cotton pellet saturated with the liquid component of the Ketac Molar for control group and Dentin Conditioner for test group (Fuji VIII) for 10 seconds. The conditioned surfaces were then washed several times with wet cotton pellets and dried with dry cotton pellets. Matrix strips and wedges were placed. A Tofflemire matrix (Ultrathin, Teledyne Getz, Elk Grove Village, USA) was applied with a matrix strip (TDV Dental, São Paulo, Brazil), and wedges (TDV Dental, São Paulo, Brazil) to each restoration. The GICs (Ketac Molar and Fuji VIII) were mixed according to the manufacturer's instruction and placed into the cavity using the smooth side of a spoon excavator (Duflex-SS White, Petrópolis, Brazil). The GIC was also placed over the previously conditioned pits and fissures. Petroleum jelly was used to coat the operator's gloved finger and a slight pressure was applied on top of the entire occlusal surface for approximately 30 seconds. This "pressfinger" technique was used to condense the material into the cavity and any adjacent pits and fissures, resulting in a sealant restoration. Excess restoration material was removed with a spoon excavator or carver (Duflex-SS White, Petrópolis, Brazil). After initial hardening of the material, the occlusion were checked with articulating paper (AccuFilm II - CE, Farmingdale, USA) and, if necessary, adjusted with a carver. Two coats of varnish (Copalite, Cooley \& Cooley, Houston, USA) were applied over the restoration to prevent dehydration. The patient was instructed not to eat for at least one hour. Local anesthesia was used only in 4 treatments.

Children in both groups were seen by a trained dental health educator and received advice on healthy eating and good oral health behavior.

\section{EVALUATION}

The clinical evaluation was carried out after 3 years by two calibrated independent examiners, which were not involved in the treatment.

Initially, visible debris and plaque were removed with the aid of an explorer. The tooth was cleaned with small wet cotton pellet and dried using cotton pellets. Clinical evaluation was performed using WHO periodontal probes, sharp sickle-shaped explorers, plane frontsurface mirrors and a light source. In addition, slides were taken at baseline and after 3-year. Duplicate examinations were carried out on a random sample of $10 \%$ of schoolchildren. The ball of the CPI probe $(0.5 \mathrm{~mm}$ in diameter) was used to measure the size of any marginal defect and the amount of wear. Restorations with codes 0,1 and 2 were regarded as successful, codes 3 to 6 were regarded as failures and cases with codes 7 and 8 were excluded from the analysis (Table 2) $[16,17]$ 
Table 1 - Specifications of the GICs Tested

\begin{tabular}{|c|c|c|c|}
\hline \multicolumn{4}{|r|}{ Glass Ionomer Cements } \\
\hline Product & Manufacturer & Batch \# & $\begin{array}{l}\text { Composition } \\
\text { Power: liquid }\end{array}$ \\
\hline Ketac-Molar & $\begin{array}{l}\text { 3M ESPE } \\
\text { Seefeld- Germany }\end{array}$ & 0108677 & $\begin{array}{l}\text { Powder: Calcium aluminum lanthan fluorosilicate glass, acrylic acid, maleic acid, copolymer, pigments } \\
\text { Liquid: Acrylic acid, maleic acid, copolymer, tartaric acid }\end{array}$ \\
\hline Fuji VIII & $\begin{array}{l}\text { GC Corporation } \\
\text { Tokyo-Japan }\end{array}$ & 0107031 & $\begin{array}{c}\text { Powder: Fluoro-Alumino-silicate glass; Pigment } \\
\text { Liquid: Distilled water; Polyacrylic acid; 2-HEMA; Dimethacrylate; Initiator }\end{array}$ \\
\hline
\end{tabular}

Table 2 - Codes used in the evaluation of the ART restorations

\begin{tabular}{|c|c|}
\hline \multicolumn{2}{|r|}{ Glass Ionomer Cements } \\
\hline Code $^{\star}$ & Description \\
\hline 0 & Present, in good condition \\
\hline 1 & Present, slight marginal defect, no repair is needed \\
\hline 2 & Present, slight wear, no repair is needed \\
\hline 3 & Present, marginal defect $0.5 \mathrm{~mm}$, repair is needed \\
\hline 4 & Present, wear $\gg .05$ mm, repair is needed \\
\hline 5 & Not present, restoration partly or completely missing \\
\hline 6 & Not present, restoration replaced by another restoration \\
\hline 7 & Tooth is missing, exfoliated or extracted \\
\hline 8 & Restoration not assessed, child is not present \\
\hline
\end{tabular}

Codes ${ }^{*} 0,1,2=$ successful; $3,4,5,6=$ failure; $7,8=$ excluded.

\section{DATA ANALYSIS}

Simple descriptive statistics were used with the chi-square test. Descriptive statistics included the computation of mean, median, standard deviation for the continuous variables. McNemar test was used to assess statistical significant differences between evaluation periods (baseline and 3-year).

Multiple logistic regression models were developed to identify factors associated with the success rate during evaluation, and potential interactions were explored. Variables that showed significant results $(p<0.05)$ in domain-specific regression models were used to develop a final model using forward stepwise logistic regression analysis, and verified using backward elimination. All possible two-way interactions were considered for all variables in the final model as well as for any variables in the candidate list obtained from the initial bivariate screen.

The kappa test was employed to verify intra- and inter-examiners reproducibility. Confidence intervals were estimated with a 95\% level for success on the binominal distribution. A difference was statistically significant if $p$ $<0.05$. Data were analyzed using the SPSS program (version 13).

\section{RESULTS}

\section{Baseline}

\section{- Descriptive}

A total of 60 schoolchildren, with a mean age of $11.59 \pm 1.6$ years (range $9-16$ years) participated of this trial. The mean DMFT was 3.48 (SD= 1.77), of which $82 \%$ teeth were decayed.

The restorations were placed in first and second permanent molars. The number of restorations placed was respectively of 34 and 26 restorations by operator. There were more restorations placed in the lower $(65 \%)$ than in the upper jaw (35\%) and more in first molars $(81.7 \%)$ than in second molars $(18.3 \%)$. The percentage of girls and boys was 58.7 and $41.3 \%$, respectively. There were no statistically significant differences between the test (Fuji VIII) and control (Ketac Molar) groups by age, gender, jaw, type of molar at baseline ( $\mathrm{x}^{2}$ test, $\mathrm{p}=0.3$ ).

Distribution of the ART restorations placed by class type is shown in Table 3. Local anesthesia was necessary in 4 treatments. In 12 deep cavities a thin layer of calcium hydroxide was applied over the deep spots.

At interview, $90 \%$ of the children reported that they did not feel any pain or discomfort during treatment while only $10 \%$ indicated they had experienced a slight pain or discomfort. Postoperative discomfort was reported by only $6 \%$ of the children. Ninety percent of the schoolchildren were willing to receive ART restorations again should a need arise.

Table 3 - Distribution of restorations according to Class Type

\begin{tabular}{|c|c|c|c|c|}
\hline & \multicolumn{2}{|c|}{$\begin{array}{c}\text { Class } \text { - }- \text { involving } \geq 2 \text { tooth } \\
\text { surfaces }\end{array}$} & \multicolumn{2}{|c|}{ Class II } \\
\hline & Ketac-Molar & FujIVIII & Ketac-Molar & FujIVIII \\
\hline $\begin{array}{l}\text { Number of } \\
\text { restorations }\end{array}$ & 17 & 19 & 13 & 11 \\
\hline Total & \multicolumn{2}{|c|}{36} & \multicolumn{2}{|c|}{24} \\
\hline
\end{tabular}




\section{Survival of restorations}

\section{- Three-Year Follow-Up}

At the 3-year follow-up, 57 restorations were assessed. The lost-to-follow-up percentages of restorations originally placed was considered very low. Only 3 schoolchildren in this study moved to other cities and could not be evaluated, all of them belonged to Ketac Molar group and were excluded of the sample (code 8).

The kappa-value for inter-examiners reproducibility was of 0.95 . Table 4 shows the status of the ART restorations at the 3-year examination by class type and GIC. Most of the ART restoration were in a good condition or had some minor defects or wear which did not warrant further treatment. There was no statistically significant difference in the restorations success between baseline and 3-year (McNemar test, $\mathrm{p}>0.05$ ).

There were no statistically significant differences between the test (Fuji VIII) and control (Ketac Molar) groups considering age, gender, jaw and teeth at 3-year $\left(\mathrm{x}^{2}\right.$ test, $\mathrm{p}>$ $0.05)$. None of the restored teeth developed caries in the 3-year evaluation period.

The success rate for Ketac Molar was $77.8 \%(\mathrm{CI}=58-91 \%)$ and for Fuji VII I was 93.4\% (CI $=78-99 \%)$. Thus, most of the ART restorations were in a good condition or had some minor defects or wear which did not warrant further treatment. In the Ketac Molar group, failure occurred in 5 restorations overall, 2 had unacceptable marginal defects, and 3 were replaced by another restoration. The failures rates of Class I involving two or more tooth surfaces and Class II were respectively 3 and 2 restorations. In the Fuji VIII group, failure occurred in 2 Class I restorations involving two or more tooth surfaces, which were replaced by another restoration.

Table 5 displays the regression final model predicting the success rate with 95\% confidence intervals. Results of logistic regression showed that only the combination of the three variables (GIC, operator, Class type) was statistically significant $(\mathrm{p}=0.036)$ in relation to survival of the ART restoration after 3-year follow-up. The other independent variables included in the analysis and not retained in the final model were the child's age, gender, jaw site, and whether the restorations were placed in first or second molars. The best performance included the combination: Fuji VIII, operator B and Class I involving two or more tooth surfaces. There were no statistically significant differences between the groups taking each variable into account: GIC $(\mathrm{p}=0.071)$, operator $(\mathrm{p}=0.059)$, restorations Class type $(\mathrm{p}=0.138)$.

Table 4 - Status of the multiple-surface ART restorations after baseline, 6, 12 and 36 months (expressed in numbers)

\begin{tabular}{|c|c|c|c|c|c|c|c|c|c|c|c|c|c|c|c|c|}
\hline \multirow{3}{*}{ Score } & \multicolumn{8}{|c|}{ Class I-involving two or more tooth surfaces } & \multicolumn{8}{|c|}{ Class II } \\
\hline & \multicolumn{4}{|c|}{ Ketac Molar $(\mathbf{n}=17)$} & \multicolumn{4}{|c|}{ Fuji VIII $(n=19)$} & \multicolumn{4}{|c|}{ Ketac Molar $(n=13)$} & \multicolumn{4}{|c|}{ FujiVIII (n= 11) } \\
\hline & $\mathrm{B}^{*}$ & 6-m & $12-m$ & 36-m & $\mathrm{B}^{\star}$ & 6-m & 12-m & 36-m & $B^{\star}$ & 6-m & 12-m & 36-m & $\mathrm{B}^{\star}$ & 6-m & 12-m & $36-m$ \\
\hline 0 & 17 & 16 & 15 & 12 & 19 & 19 & 19 & 17 & 13 & 12 & 9 & 5 & 11 & 11 & 10 & 10 \\
\hline 1 & -- & -- & -- & -- & -- & -- & -- & -- & -- & -- & 3 & 4 & -- & - & 1 & 1 \\
\hline 2 & -- & -- & -- & - & -- & -- & -- & -- & -- & -- & - & - & -- & -- & -- & -- \\
\hline 3 & -- & -- & 1 & 2 & -- & -- & - & -- & -- & -- & -- & -- & -- & - & -- & -- \\
\hline 6 & -- & -- & -- & 2 & -- & -- & -- & 2 & -- & 1 & 1 & 2 & -- & -- & -- & -- \\
\hline 8 & -- & 1 & 1 & 1 & -- & -- & - & -- & -- & -- & -- & 2 & -- & - & -- & -- \\
\hline
\end{tabular}

Table 5 - Logistic regression model for status of success rate at the 3-year follow-up (success $=0$, insuccess $=1$ )

\begin{tabular}{lcccccc}
\multicolumn{1}{c}{ Variables } & $\begin{array}{c}\text { Regression } \\
\text { coefficient }\end{array}$ & Standard error & $\mathbf{p}$ & Odds Ratio & \multicolumn{2}{c}{ 95\% Cl for OR } \\
Lower & Upper \\
- GlC Ketac Molar (0) & -1.670 & 0.924 & 0.071 & 0.188 & 0.031 & 1.150 \\
Fuji VIII (1) & -2.308 & 1.223 & 0.059 & 0.099 & 0.009 & 1.094 \\
- Operator A (0) B (1) & 1.342 & 0.906 & 0.138 & 3.828 & 0.649 & 22.585 \\
- Class type & & & & & &
\end{tabular}




\section{DISCUSSION}

In the present study, 57 of the 60 restorations were evaluated after 3-year follow-up. The drop-out-rate in this study was very low (5\%) compared to previous ART studies, which were usually more than 30\% [7,11,12]. In these studies the reason was, in general, attributed to the children's irregular attendance at school. In present study, only 3 schoolchildren were not evaluated because they had moved to other cities. In average, three appointments were required to complete the evaluation and one-third of the patients received home visits. Then, this low lost-to-follow-up rate was possible by particular attention that was given to the patient's chart that also included the parents and friends' addresses and phone numbers, as well as the school record system.

The present 3-year results of multiplesurface ART restorations are very encouraging and confirm a promising performance of the ART restorations observed after 6 months and 1 year by Cefaly et al $[16,17]$. Regarding to cavity type, $100 \%$ of Class I restorations were considered successful for Fuji VIII and $86.7 \%$ for Ketac Molar. For Class II, the success rates were 83.4\% for Fuji VIII and $66.7 \%$ for Ketac Molar. There was no statistically significant difference in the restorations between baseline and 3-year. In a survival rate of proximal ART restorations in primary molars, it was observed that the choice of medium-sized proximal cavities resulted in better survival rates for this technique [13]. Additionally, low survival rate of proximal ART restorations in primary molars was associated with the presence of cervical marginal-gaps [18].

The main reason for failure of restorations in the present study was "gross marginal defect" observed in the control group (Ketac Molar). However, there was not statistically significant difference between the GIC's performance ( $\mathrm{p}=$ $0.071)$. The high success rates of the restorations in this study in both groups after 3 years may be also result of the meticulous care with removing carious dentine from enamel-dentine junction (EDJ), as well as the preparation of retentive grooves in the EDJ that could have enhanced bonding. Wang et al. (2004) [12] reported that the failure of the restorations was probably due to the lack of retention in prepared teeth.
The clinical criteria used to assess the quality of restorations in the present study (Table 2) were similar to those used in other ART studies $[16,17,19]$. These criteria are appropriate for clinical evaluations carried out in a field setting and are defined by a description of the reason for success or failures of the restorations $[4,8,16,17,19]$. In this study, similarly as others reporting ART restoration replacement by another treatment, these scenarios were classified as failure $[12,16,17,20]$. As a result of this divergence, the present study might have reported higher failure rate compared to other ART studies that excluded these cases [7]. In this study, replacement of ART restorations was likely to be related to defective or missing restorations, because the utilization of dental services by the schoolchildren is frequently related to the pain. Other study considered the possibility that a dentist, when treating caries in other teeth could replace an existing ART restoration by a new one, usually amalgam [21].

The ART approach using GIC's has been advocated because of its attractive features, but the earlier ART studies indicated that the mechanical strength of restorations might not be sufficient to reliably restore large stress-bearing areas such as in certain large class I and class II situations. ART restorations should ideally be restricted to relatively small cavities surrounded by sufficient tooth structure [8]. More recent studies with HV GIC's have reported better results than the earlier ART studies due to their improved handling and mechanical properties. However, these materials should still be limited to contactfree areas $[4,12,20]$. On the other hand, in Brazil the tooth loss is still a serious public health problem and the dental caries is the main cause of teeth extraction [22]. In the present study, if the indication of this restorative treatment had been restricted to small lesions, probably the majority of the treated teeth would have been extracted in this recall period. It was observed in other study that decayed teeth generally remained untreated until being extracted [19].

The results of the present study show that the caries-preventive effect of HV GIC and RM GIC were considered similar. None failure was due to caries development, suggesting a high level of effectiveness after 3 years, regardless of the high caries experience (82\%). The proportion of secondary caries as a failure in the ART 
restorations is also very low in other studies [8,21]. Lo \& Holmgren, (2001) [21] reported that when an ART restoration was missing, the exposed dentine surface of the cavity was usually found to be hard, indicating that caries was not progressing. In this study, none restoration was missing, but one restoration failed due to the gross marginal defect. It is interesting to note that hypermineralization of the exposed dentin surface was also observed. This could be due to a number of factors including the removal of all infected dentin during the ART cavity preparation, the effect of remineralization of the GIC's, and the effect of saliva and fluoride $[2,3,23]$. Systematic review also regarding to primary molars evidenced that RM GIC can perform successfully in small to moderate sized class II restorations; in contrast conventional GIC cannot be recommended for these cavities [24].

The commonly held belief that the ART approach is easy has been questioned by several authors $[7,8,19]$. The survival results varied widely per operator and revealed that less experienced operators obtain worse results compared to experienced ones [8, 10, 13, 19]. For example, in Zimbabwe, senior dentists performed better than junior dental therapists [7] whilst in Pakistan, one of the five dentists performed worse than the colleagues [25]. In Syria, the operator-specific survival percentages after 3 years for all restorations varied widely per operator [10]. In the present study, the background of the two operators was similar. Although some operator effect is expected in any dental treatment procedure, the present findings suggest that is necessary a training course on the rationale and technique of the ART approach before practicing the approach for that the operators can produce reliable results. This observation was in according to those presented in literature $[7,8,10,25]$. Lastly, in proximal cavities it was rather difficult to control cavity contamination from saliva or blood in cavities with margins close to the gingival thereby having a detrimental effect on bonding $[7,8,19]$. Thus, the use of a chair side assistant might also have contributed to the high success rates, in this study, since the operators could spend more time on saliva control after conditioning while the assistant was mixing the glass-ionomer. This observation was also reported for others ART studies that included the insufficient cleaning of the cavity, improper mixing of the GIC's powder/ liquid, saliva contamination, insufficient or no conditioning of the cleaned tooth cavity and level of cooperation of the patients as number of reasons for failures of the ART restorations $[7,8,12]$.

The multivariate analyses were useful in singling out factors that significantly affected the results and these analyses clearly demonstrated the factors that were significant for enhanced longevity of the restorations. The better results were reflected in the interaction between the operator (B), GIC (Fuji VIII), and the Class I involving two or more tooth surfaces.

In this study, it was particularly encouraging to find that although a local anesthetics was used in 4 schoolchildren that reported discomfort during treatment, 56 schoolchildren did not feel any pain or discomfort during treatment, as well as, they related that were satisfied with the treatment and they were willing to receive other ART restorations in the future. This very high acceptance of the ART approach by patients can be attributable to the non-use of rotary instruments and anesthetic injections combined with the provision of treatment within a familiar, non-threatening environment $[8,25]$. Other speculative reason could be the expressed patient-friendliness of the ART approach $[8,25]$. Several studies have shown that dental anxiety and pain or discomfort are mainly associated with highly invasive procedures such as 'drilling' and 'injections' [6,25].Neither procedure is usually needed in the ART approach $[4,21]$.

There is a consensus that further research into the use RM GIC with ART is therefore warranted because the literature presents only few short-term studies [3].

\section{CONCLUSIONS}

The results suggest that multiple-surface ART restorations shown to be highly appropriate, effective and acceptable in permanent teeth after 3-year. The ART is an approach that has its applications for providing dental care outside the traditional clinical setting and is not dependent upon expensive and sophisticated dental equipment. Thus, ART approach could be adopted as treatment of choice for use in dental programs in the school environment. 


\section{ACKNOWLEDGEMENTS}

The authors gratefully acknowledge the schoolchildren, their parents and staff at the schools in Bauru for their assistance and cooperation in this study. This study was supported by a grant from the Government of the Brazil through The State of São Paulo Research Foundation(FAPESP), Grant\# 01/04943-0.

\section{REFERENCES}

1. Frencken JE, Leal SC, Navarro MF. Twenty-five-year atraumatic restorative treatment (ART) approach: a comprehensive overview. Clin Oral Investig. 2012 0ct;16(5):1337-46.

2. Holmgren CJ, Roux D, Doméjean S. Minimal intervention dentistry: part 5. Atraumatic restorative treatment (ART)--a minimum intervention and minimally invasive approach for the management of dental caries. $\mathrm{Br}$ Dent J. 2013 Jan;214(1):11-8.

3. Molina GF, Cabral RJ, Frencken JE. The ART approach: clinical aspects reviewed. J Appl Oral Sci. 2009;17 Suppl:89-98.

4. Frencken JE, Holmgren CJ. ART: a minimal intervention approach to manage dental caries. Dent Update. 2004 Jun;31(5):295-8, 301.

5. Pilot T. Introduction-ART from a global perspective. Community Dent Oral Epidemiol. 1999 Dec;27(6):421-2.

6. Schriks MC, van Amerongen WE. Atraumatic perspectives of ART: psychological and physiological aspects of treatment with and without rotary instruments. Community Dent Oral Epidemiol. 2003 Feb;31(1):1520.

7. Frencken JE, Makoni F, Sithole WD, Hackenitz E. Three-year survival of one-surface ART restorations and glass-ionomer sealants in a school oral health programme in Zimbabwe. Caries Res. 1998;32:119-26.

8. Holmgren CJ, Lo EC, Hu D, Wan H. ART restorations and sealants placed in Chinese school children - results after three years. Community Dent Oral Epidemiol. 2000;28:314-20.

9. Taifour D, Frencken JE, Beiruti N, van 't Hof MA, Truin GJ. Effectiveness of glass-ionomer (ART) and amalgam restorations in the deciduous dentition: results after 3 years. Caries Res. 2002 Nov-Dec;36(6):437-44.

10. Taifour D, Frencken JE, Beiruti N, van't Hof MA, Truin GJ, van Palenstein Helderman WH. Comparison between restorations in the permanent dentition produced by hand and rotary instrumentation-survival after 3 years. Community Dent Oral Epidemiol. 2003 Apr;31(2):122-8.

11. Yu C, Gao XJ, Deng DM, Yip HK, Smales RJ. Survival of glass ionomer restorations placed in primary molars using atraumatic restorative treatment (ART) and conventional cavity preparations: 2-year results. Int Dent J. 2004 Feb;54(1):42-6.
12. Wang L, Lopes LG, Bresciani E, Lauris JR, Mondelli RF, Navarro MF Evaluation of Class I ART restorations in Brazilian schoolchildren: threeyear results. Spec Care Dentist. 2004 Jan-Feb;24(1):28-33.

13. Kemoli AM, van Amerongen WE, Opinya G. Influence of the experience of operator and assistant on the survival rate of proximal ART restorations: two-year results. Eur Arch Paediatr Dent. 2009 Dec;10(4):227-32.

14. Tyas MJ. Milestones in adhesion: glass ionomer cements. J Adhes Dent. 2003:5:259-66.

15. Mickenautsch S. How well are GIC product labels related to current systematic review evidence? Dent Update. 2011 Nov;38(9):634-8, 641-2, 644.

16. Cefaly DFG, Barata TJE, Tapety CMC, Bresciani E, Navarro MFL. Clinical evaluation of multisurface ART restorations. J Appl Oral Sci. 2005;13:159.

17. Cefaly DF, Barata TJ, Bresciani E, Fagundes TC, Lauris JR, Navarro MF Clinical evaluation of multiple-surface ART restorations: 12 month follow-up. J Dent Child. 2007;74:203-8.

18. Kemoli AM, van Amerongen WE. Effects of oral hygiene, residual caries and cervical marginal-gaps on the survival of proximal atraumatic restorative treatment approach restorations. Contemp Clin Dent. 2011;2:318-23

19. Mallow PK, Durward CS, Klaipo M. Restoration of permanent teeth in young rural children in Cambodia using the atraumatic restorative treatment (ART) thechnique and Fuji II glass ionomer cement. Int J Paediatr Dent. 1998;8:35-40.

20. Souza EM, Cefaly DFG, Terada RSS, Rodrigues CC, Navarro MFL. Clinical evaluation of the ART technique using high density and resin-modified glass ionomer cements. Oral Health Prev Dent. 2003;3:201-7.

21. Lo EC, Holmgren CJ. Provision of Atraumatic Restorative Treatment (ART) restorations to Chinese pre-school children-a 30-month evaluation. Int J Paediatr Dent. 2001 Jan;11(1):3-10.

22. Jovino-Silveira RC, Caldas Ade F Jr, de Souza EH, Gusmão ES. Primary reason for tooth extraction in a Brazilian adult population. Oral Health Prev Dent. 2005; 3:151-7.

23. Ngo HC, Mount G, Mc Intyre J, Tuisuva J, Von Doussa RJ. Chemical exchange between glass-ionomer restorations and residual carious dentine in permanent molars: an in vivo study. J Dent. 2006;34:608-13.

24. Chadwick BL, Evans DJ. Restoration of class II cavities in primary molar teeth with conventional and resin modified glass ionomer cements: a systematic review of the literature. Eur Arch Paediatr Dent. 2007;8:1421.

25. Rahimtoola S, van Amerongen E, Maher R, Groen H. Pain related to different ways of minimal intervention in the treatment of small caries lesions. ASDC J Dent Child. 2000 Mar-Apr;67(2):123-7,83.

\section{Ticiane Cestari Fagundes}

(Corresponding address)

Rua José Bonifácio, 1193, Araçatuba,

São Paulo, Brazil

E-mail address: ticiane_f@hotmail.com 